\title{
Comparative Histomorphology of the Ovary and the Oviduct in Rabbits and Pigeons
}

\author{
Helga Bedan Ishaya ${ }^{1} \quad$ Imelda Omaga $^{1}$ Nathan Isaac Dibal ${ }^{1}$ Martha Orendu O. Attah ${ }^{1}$ \\ ${ }^{1}$ Department of Human Anatomy, University of Maiduguri, Borno \\ State, Nigeria \\ J Morphol Sci 2018;35:242-245. \\ Address for correspondence Nathan Isaac Dibal, BSc, MSc, \\ Department of Human Anatomy, University of Maiduguri, P.M.B 1069 \\ Maiduguri, Borno State, Nigeria. Zip code 600233 \\ (e-mail: nathandibal@gmail.com).
}

\begin{abstract}
Keywords

- histomorphology

- rabbit

- pigeon

- uterine tube

- oviduct and ovary

Introduction Knowledge of the evolutionary relationship between different classes of vertebrates can be obtained through a comparative study of their structures, forms, functions, and of the mode of development of the structures. Birds and mammals are vertebrates with different modes of reproduction, that is, oviparity in birds and viviparity in mammals. The aim of the present study is to compare the histomorphology of the ovaries and of the oviducts/uterine tubes in rabbits and pigeons. The present study highlights the histological and morphological differences that bring about the production of eggs in birds and the production of fully developed fetuses in mammals. Materials and Methods Five rabbits and five domestic pigeons were anesthetized with chloroform and sacrificed. The ovaries and the oviducts/uterine tubes were dissected and fixed in Bouin fluid and processed for a light microscopic study.

Results The result showed paired ovaries and uterine tubes in rabbits that unite at the isthmus to form a single uterus that opens into the vagina, with only the left ovary and oviduct appearing as a compact body with distinct infundibulum, magnum, isthmus, uterus and vagina in pigeons. Photomicrographs of the ovaries of rabbits showed parenchyma cells with primary follicles, while the ovaries of pigeons showed developing follicles and yolk granules. Both the oviducts of rabbits and of pigeons showed a highly folded mucosa with a thick muscular wall.

Conclusion The differences observed in the structures of the ovaries and of the oviducts of rabbits and pigeons might be due to their different reproductive functions in parturition (viviparity and oviparity, respectively).
\end{abstract}

\section{Introduction}

Comparative anatomy is the study of the differences and similarities in the morphology, forms and functions of structures in different classes of animals. ${ }^{1}$ These can be used to justify why certain organs are present in a particular specie of animal while absent in others. The major reason for this is the fact that functional structures tend to develop, but those that are not constantly used normally regress into vestigial organs. Knowledge of the evolutionary relationship between different classes of vertebrates can be obtained through a comparative study of their structures, forms, functions, and of the mode of development of the structures. Birds and mammals are vertebrates with different modes of reproduction, that is, oviparity in birds and viviparity in mammals. ${ }^{2}$ Comparative morphology rests almost entirely on the fact that there are various kinds of relationships between the structures of different organisms and within individuals, as well as between structures, functions, organisms and environments. ${ }^{3}$

Rabbits (Oryctolagus cuniculus) are small- to medium-sized hopping mammals of the Leporidae family, with long legs and a short tail, while pigeons are birds of the Columbidae family, with a stout body, short neck, and a short slender beak. Pigeon received

March 1, 2017

accepted

August 25, 2018

published online

December 12, 2018
DOI https://doi.org/

10.1055/s-0038-1675226. ISSN 2177-0298.
Copyright (e) 2018 by Thieme Revinter

Publicações Ltda, Rio de Janeiro, Brazil
License terms

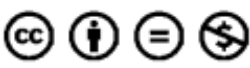


is a French word that is derived from the Latin pipio, which means a peeping chick. ${ }^{4}$ The passageway from the ovaries to the outside of the body in other vertebrates (including birds) is known as the oviduct, but in mammals, the egg passes through the uterine or fallopian tubes to be implanted in the uterus. Therefore, the part of the oviduct before the uterus is known as the uterine or fallopian tubes. The presence of a single ovary/ oviduct in most birds was believed to be a modification by adaptation for the survival of the embryo that allows the calcification of a single egg at a time, thus preventing physical contact between the eggs, which could lead to malformations. ${ }^{5}$

A comparative histomorphological study of the uterus in laying hens and ducks showed that hens have a greater uterine weight and length than ducks. ${ }^{6}$ The left oviduct of rheas (Rhea americana) is developed as a long tube, and is subdivided into the infundibulum, the magnum, the isthmus, the uterus, and the vagina. ${ }^{7} \mathrm{~A}$ thin-walled region between the magnum and the isthmus, free of glands and considered as an area of transition called zona translucent, is found in the female reproductive tract of mature ostriches. ${ }^{8}$ The hypothesis of symmorphosis postulates that structural design resulting from morphogenesis is regulated to match the functional demand. Therefore, the functional requirements of an organ system vary with its structural design. ${ }^{9}$ The aim of the present study is to compare the histomorphology of the female reproductive systems (ovaries and oviducts/uterine tubes) in pigeons (birds) and rabbits (mammals).

\section{Materials and Methods}

Five domestic pigeons and five rabbits (11-14 months old) were purchased from a local sales man at the Monday market in Maiduguri, Borno State, Nigeria. The animals were quarantined in the animal house of the Department of Human Anatomy of the University of Maiduguri for 2 weeks. They were fed with standard diet (Grower Mash, Grand Cereals Limited, Jos, Nigeria) and water ad libitum. The research was approved by the Department of Human Anatomy of the University of Maiduguri. The animals were anesthetized with chloroform and sacrificed. The ovaries, the oviducts/uterine tubes, and the uteri were dissected both in the pigeons and in the rabbits. The organs were fixed in Bouin fluid, dehydrated in a graded series of ethanol, embedded in paraffin wax, sectioned using a rotary microtome at $5 \mu \mathrm{m}$, and stained with hematoxylin and eosin $(\mathrm{H}$ \& E) for a light microscopic study.

\section{Results and Discussion}

Rabbits were observed to have paired ovaries, which were small compact bodies that lie on either side of the fallopian tubes and are attached to the dorsal wall of the abdominal cavity by the mesovarium (-Fig. $\mathbf{1}$ ), which is in line with previous studies ${ }^{10,11}$ while in the pigeons, only the left ovary was observed, which was not compact and was attached to the anterior lobe of the left kidney by the mesovarium (-Fig.2), which is in line with a previous study that reported the presence of only the left ovary in domestic pigeons, ${ }^{12}$ but is in contrast with the studies that showed the occurrence of

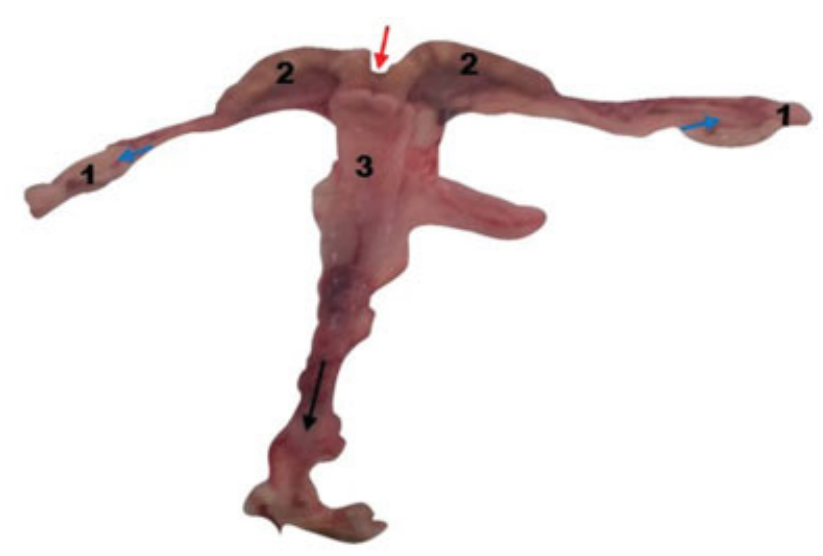

Fig. 1 The ovaries and the oviducts of rabbits: ovaries (1), infundibulum (blue arrows), magnum (2), uterus (3), vagina (black arrow), isthmus (red arrow).

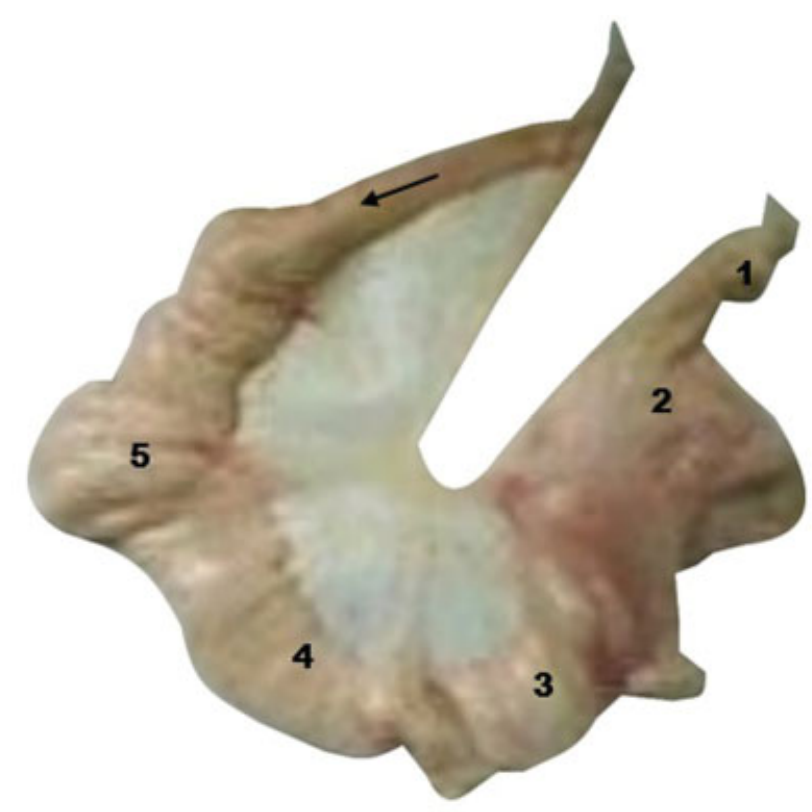

Fig. 2 The ovary and the oviduct of pigeons: ovary (1), infundibulum (2), magnum (3), isthmus (4), uterus (5), vagina (black arrow).

right ovaries in long-eared owls, common buzzards, sparrow hawks, flightless kiwis, and goshawks. ${ }^{5,13}$ In rabbits, the part of the oviduct before the uterus is paired and known as uterine tubes, which extend from the ovaries to the uterus, which is in line with a previous study. ${ }^{14}$ The uterine tubes consist of paired infundibula, magna (the site of fertilization), and isthmi, with a single uterus (the site of implantation) that ends at the vagina (the birth canal) $(-$ Fig. 1 ), while in pigeons, only one oviduct (in the left) was observed, which is in contrast with a previous study that reported the presence of paired oviducts in eagles, falcons, and vultures. ${ }^{15}$ The oviduct of the pigeon extends from the ovary to the cloaca, and consists of the infundibulum (the site of fertilization), the magnum (the site of the formation of the egg white), the isthmus (the site of the formation of the shell membrane), the uterus/shell gland, and the vagina (-Fig. 2), which is similar to previous studies that showed that the 


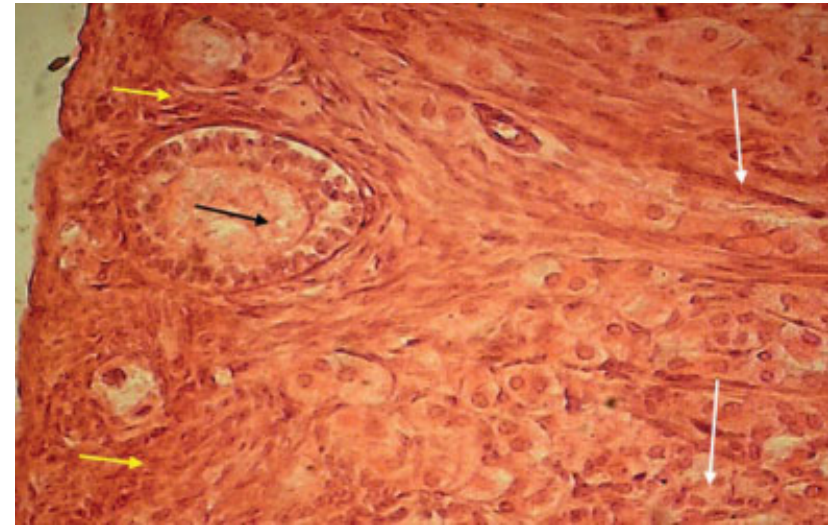

Fig. 3 Photomicrograph of a rabbit ovary showing the cortex (yellow arrows), with primary follicle (black arrow), and the medulla (white arrows). Hematoxylin and eosin (H\&E) x400.

oviducts of rheas, native chickens of Bangladesh, Turkey hens, and reptiles (Caiman latirostris) consist of the infundibulum, the magnum, the isthmus, the uterus/shell gland, and the vagina. ${ }^{16-20}$ Both in rabbits and in pigeons, the oviduct/ uterine tube lacks striation, which is in contrast with an earlier report on ostriches that showed a striated oviduct. ${ }^{8}$

The photomicrographs of the ovaries of rabbits showed parenchyma cells with primary follicles ( - Fig. 3 ), while the ovary of pigeons showed developing follicles and yolk granules ( - Fig. 4). The photomicrographs of the uterine tube and of the uteri of rabbits showed a highly folded mucosa with a thick muscular wall ( $\mathbf{- F i g . 5}$ and $\mathbf{6}$ ), which is in line with the findings of previous studies that showed highly folded mucosa in the oviducts of armadillos and crocodilian, ${ }^{14,19}$ while the oviducts of pigeons showed a thick muscular wall with mucosal folds projecting into the lumen (-Fig. 7), which is similar to the findings of a previous study that reported a highly folded mucosa within the oviduct (magnum) of C. latirostris. ${ }^{19}$

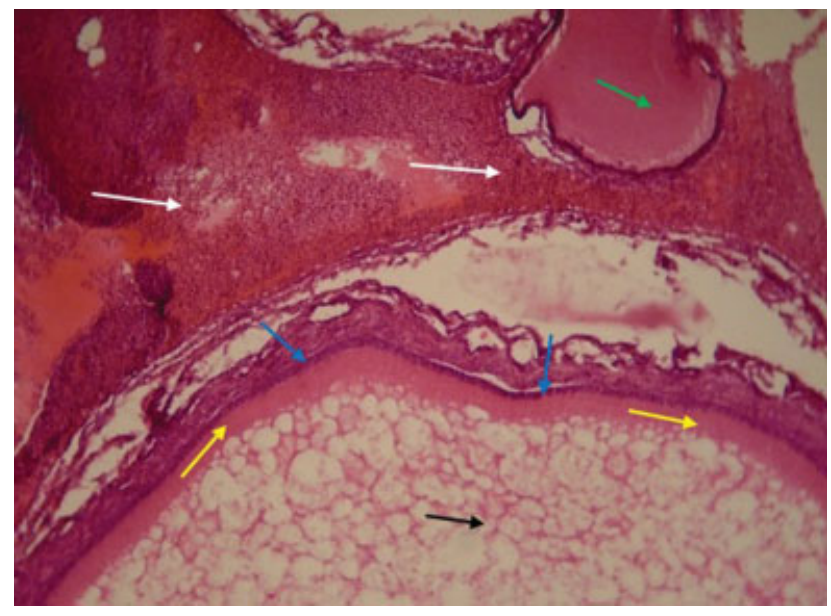

Fig. 4 Photomicrograph of a pigeon ovary showing yolk granules (black arrow), the plasma membrane of the egg (yellow arrows), granulose cells (blue arrows), developing follicles (green arrow), and vascular ovarian stroma (white arrows). Hematoxylin and eosin (H\&E) x400.

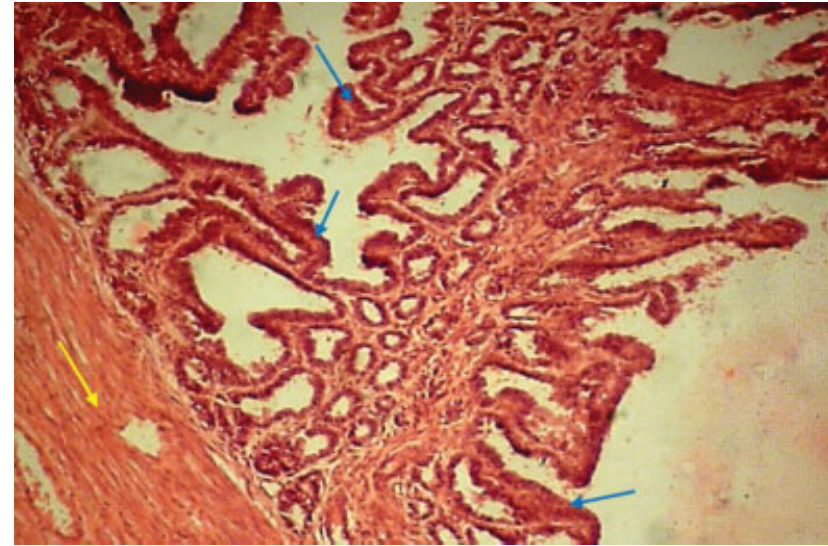

Fig. 5 Photomicrograph of a rabbit oviduct showing a highly folded mucosa (blue arrows), and the muscular wall (yellow arrow). Hematoxylin and eosin (H\&E) $\times 120$.

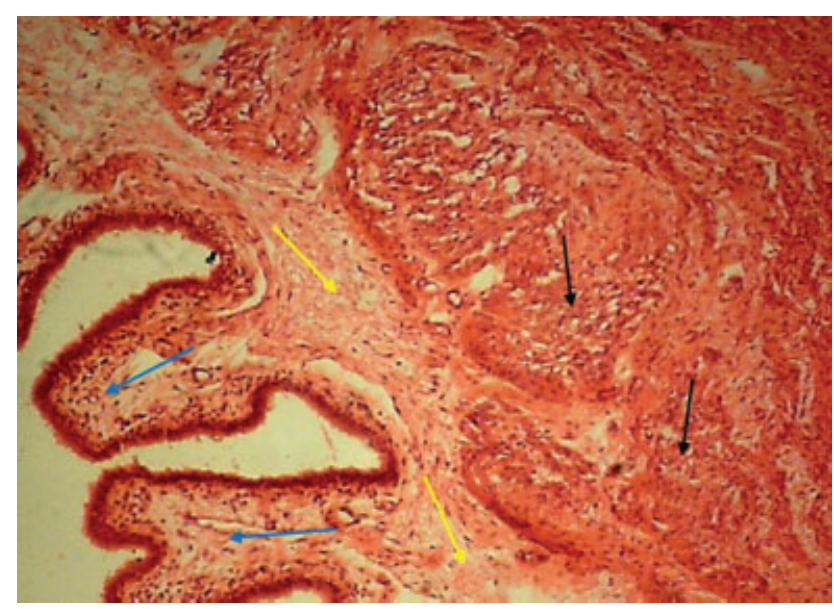

Fig. 6 Photomicrograph of a rabbit uterus showing a highly folded mucosa (blue arrows), the lamina propria (yellow arrows), and the muscular layer (black arrows). Hematoxylin and eosin (H\&E) x120

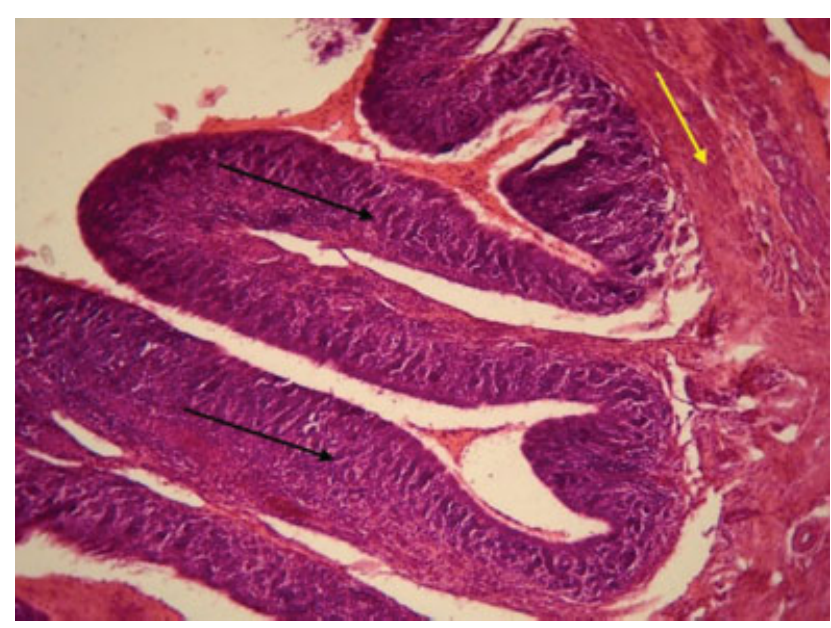

Fig. 7 Photomicrograph of a pigeon oviduct showing a thick muscular layer (yellow arrow), and long mucosal folds (black arrows) projecting into the lumen. Hematoxylin and eosin (H\&E) x400. 


\section{Conclusion}

Rabbits have paired uterine tubes that extend from the paired ovaries and unite at the isthmus to form a single uterus, while pigeons have a single left oviduct consisting of the infundibulum, the magnum, the isthmus, the uterus/shell gland, and the vagina. Histologically, the ovaries of rabbits are made up of parenchyma cells with primary follicle, while the ovaries of pigeons are made up of developing follicles and yolk granules. Both the uterine tube of rabbits and the oviduct of pigeons have a thick muscular wall and a highly folded mucosa. The differences in the structure of the uterine tubes and of the oviduct in rabbits and pigeons might be due to their different reproductive function in different types of parturition, which are viviparity in rabbits, and oviparity (laying of eggs) in pigeons.

Conflicts of Interest

The authors have no conflicts of interest to declare.

\section{References}

1 Cosans CE, Frampton M. History of Comparative Anatomy. In: eLS. John Wiley \& Sons, Ltd: Chichester; 2015:1-8

2 Blackburn DG. Viviparity and Oviparity: Evolution and Reproductive strategies. Encyclop Reprod 2006;4:994-1003

3 Zangerl R. The methods of comparative anatomy and its contribution to the study of evolution. Evolution 1948;2(04):351-374

4 Douglas H. Pigeon Online Etymology Dictionary. http://www. etyoline.com accessed $24^{\text {th }}$ July, 2018

5 Johnson AL. The avian ovary and follicle development: some comparative and practical insights. Turk J Vet Anim Sci 2014; 38:660-669

6 Mohammadpour AA. Comparative histomorphological study of uterus between laying hen and duck. Pak J Biol Sci 2007;10(19): 3479-3481
7 Parizzi RC, Santos JM, Oliveira MF, et al. Macroscopic and microscopic anatomy of the oviduct in the sexually mature rhea (Rhea americana). Anat Histol Embryol 2008;37(03):169-176

8 Sharaf A, Eid W, Abuel-Aha AA. Age Related Morphology of the Ostrich Oviduct (isthmus, uterus and vagina). Bulg J Vet Med 2013;16:145-158

9 Weibel ER, Taylor CR, Hoppeler H. The concept of symmorphosis: a testable hypothesis of structure-function relationship. Proc Natl Acad Sci U S A 1991;88(22):10357-10361

10 Popesko P, Rajtova V, Horak J. Colour atlas of Anatomy of small laboratory Animals. London: Wolfe Publishing Ltd; 1990

11 Capello V. Surgical Techniques for neutering the female pet Rabbit. Exotic DVM 2005;7:15-21

12 Kigir LS, Silvachelvan SN, Kwari HD, et al. Gross and Microscopic Changes in the Gonads of Male and Female Domestic Pigeon. New York Sci J 2010;3:108-111

13 Rodler D, Stein K, Korbel R. Observations on the right ovary of birds of prey: a histological and immunohistochemical study. Anat Histol Embryol 2015;44(03):168-177

14 Codon ST, Casanave EB. Morphology and Histological Annual changes of the oviduct of Chaetophraetus villosus (Mammalia, Xenarthra, Dasypodidae). Int J Morphol 2009;27:355-360

15 Coles BH. Essentials of Avian Medicine and Surgery, 3rd ed. Oxford, UK: Blackwell Publishing; 1997

16 Kar AB. Studies on the ligaments of the oviduct in the domestic fowl. Anat Rec 1947;97(02):175-195

17 Kuhmel W, Busch LC. Surface Morphology of the Rabbit uterus and oviduct during oestrus. Anat Embryol (Berl) 1979;159:189-195

18 Mishra D, Sultana N, Masum MA, Rahman S. Gross and Histomorphological Studies of the Oviduct of Native Bangladesh Chicken. Bulg J Vet Med 2014;12:9-15

19 Machado-Santos C, Santana LNS, Vargas LF, Abidu-Figueredo M, Brito-Gitirana L, Chagas MA. Histological and Immunohistochemical study of ovaries and oviducts of the juvenile female of Caiman latirostris (Crocodilia: Alligatoridae). Zoologia 2015;32:395-402

20 Mahmud MA, Shaba P, Onu J, et al. Gross Morphological and Morphometric Studies of Oviduct in Three Genotypes of Nigerian Indigenous Laying Chickens. J Dairy Vet Anim Res 2017; 5:00151 